\title{
X-AND $\gamma$-RAY MEASUREMENTS DURING THE 1972, AUGUST 2 AND 7 LARGE SOLAR FLARES
}

\author{
R. TALON and G. VEDRENNE \\ Centre d'Etude Spatiale des Rayonnements - B.P. 4057-31029, Toulouse Cedex, France \\ and
}

\begin{abstract}
A. S. MELIORANSKY, N. F. PISSARENKO, V. M. SHAMOLIN, and O. B. LIKIN Institut de Physique Spatiale I.K.I., Académie des Sciences d'U.R.S.S., Moscou, U.R.S.S.
\end{abstract}

\begin{abstract}
The solar X-and gamma-ray experiment aboard Prognoz 2 recorded solar gammaradiation bursts during the 1972, August 2, 4 and 7 events. This work analyses the general evolution of the August 2 and 7 events and the possible evidence for $\gamma$-ray lines during these two events.
\end{abstract}

\section{The Experiment}

The satellite Prognoz 2 was launched on 29 June 1972 for the purpose of studying the effects of solar activity. The satellite orbit is inclined at $65^{\circ}$, with an apogee of $200000 \mathrm{~km}$ and a perigee of $1000 \mathrm{~km}$.

At launch time the projection of the abside line on the ecliptic plane was close to the direction of the Sun.

The scientific equipment aboard the satellite consists of detectors for studying temporal changes in electromagnetic radiation and charged solar particles.

For the large events of 1972, August 2 and 7, data were analyzed from the RS 1 and SGL 1 X-ray spectrometers, a gamma radiation spectrometer from the Signe 1 experimert, and several charged particle detectors, all of which are described below.

The RS 1 spectrometer consists of a proportional counter shielded by passive (copper) and active (gas counter) anticoincidences. Its volume is $400 \mathrm{~cm}^{3}$, and it is filled with a mixture of $90 \%$ xenon and $10 \%$ methane under a pressure of approximately $0.8 \mathrm{~atm}$. The $0.5 \mathrm{~cm}^{2}$ area window of the counter is made of Beryllium $60 \mu$ thick.

The count rates of this detector were recorded in four energy ranges:

$$
\begin{array}{lll}
\Delta E_{1} \simeq 4.1-9.7 \mathrm{keV}, & & \Delta E_{2} \simeq 9.7-19.0 \mathrm{keV} \\
\Delta E_{3} \simeq 19.0-33 \mathrm{keV}, & \Delta E_{4} \simeq 33-54 \mathrm{keV}
\end{array}
$$

The detailed characteristics of the apparatus have been given elsewhere (Grigorov et al., 1974).

The SGL 1 spectrometer is designed to measure the spectrum of $\mathrm{X}$-rays in the range $38-340 \mathrm{keV}$. This energy interval is divided as follows:

$$
\begin{array}{ll}
\Delta E_{5} \simeq 38-77 \mathrm{keV}, & \Delta E_{6} \simeq 77-130 \mathrm{keV} \\
\Delta E_{7} \simeq 130-250 \mathrm{keV}, & \Delta E_{8} \simeq 250-340 \mathrm{keV}
\end{array}
$$

This detector is a scintillation counter composed of a Cs I(T1) crystal, $39 \mathrm{~mm}$ in diameter and $8 \mathrm{~mm}$ thick, and an FEO 53 photomultiplier. The detector is shielded 
over $4 \pi$ by a plastic scintillator $0.5 \mathrm{~cm}$ thick. The entry window consists of a sheet of $0.1 \mathrm{~mm}$ aluminum and $0.1 \mathrm{~mm}$ of reflective material. In addition to the X-ray data, this detector gives information on events when $\gamma$-rays (energy $>340 \mathrm{keV}$ ) and charged particles interact in the main detector. The detailed description of this SGL 1 apparatus is given elsewhere (Kudriatsev et al., 1973).

In the Signe 1 apparatus designed to study solar gamma radiation and neutrons, a Stilbene scintillator, $38.1 \mathrm{~mm}$ in diameter and $38.1 \mathrm{~mm}$ high, shielded by a plastic scintillator, is used. The Compton electrons and recoil protons due respectively to photon and neutron interactions in the stilbene are detected by a Radiotechnique $416 \mathrm{~F}$ photomultiplier. The anticoincidence plastic scintillator coupled to a RCA 4441 A photomultiplier rejects charged particles. Pulse shape discrimination separates electrons from protons. The gamma radiation is measured in the following intervals:

$$
\begin{array}{rlrl}
E_{9} & \simeq 0.4-0.7 \mathrm{MeV}, & & E_{10} \simeq 0.7-1 \mathrm{MeV} \\
E_{11} \simeq 1-1.6 \mathrm{MeV}, & & E_{12} \simeq 1.6-2.4 \mathrm{MeV} \\
E_{13} \simeq 2.4-2.9 \mathrm{MeV}, & E_{14} \simeq 2.9-3.9 \mathrm{MeV} \\
E_{15} \simeq 3.9-8.1 \mathrm{MeV}, & E_{16} \simeq 8.1-11.8 \mathrm{MeV}
\end{array}
$$

The detector works in two successive modes:

(1) Recording gamma photons between $\Delta E_{9}-\Delta E_{14}$

(2) Recording gamma photons between $\Delta E_{14}-\Delta E_{16}$

Each phase lasts $82 \mathrm{~min}$; a more detailed description of this experiment has appeared in Vedrenne et al. (1973).

The count rate is recorded in the RS 1 and SGL 1 apparatus and in mode (1) of the Signe 1 apparatus once every $41 \mathrm{~s}$ and in mode (2) of the Signe 1 apparatus once every $160 \mathrm{~s}$.

Data for proton fluxes were obtained above $500 \mathrm{MeV}$ from a Cerenkov counter (Blioudov et al., 1974) and above $15 \mathrm{MeV}$ from an STS 5 discharge counter. The general characteristics of these detectors are given in Table I.

TABLE I

Detector characteristics

Detector

(1) $\mathrm{Be} 60 \mu$ window proportional counter

(2) Cs I(T1) crystal scintillation counter, $38-340 \mathrm{keV}$ $8 \mathrm{~mm}$ thick, $39 \mathrm{~mm}$ diameter

(3) Stilbene scintillation counter $38.1 \mathrm{~mm}$ diameter, $38.1 \mathrm{~mm}$ thick

(4) STS 5 gas discharge counter

(5) Cerenkov counter
Energy range

$2.3-28 \mathrm{keV}$

$0.35-11.8 \mathrm{MeV}$

Protons $E>15 \mathrm{MeV}$

Electrons energy $>1 \mathrm{MeV}$

Protons $E \geqslant 500 \mathrm{MeV}$

Protons $E \geqslant 100 \mathrm{MeV}$
Area $\left(\mathrm{cm}^{2}\right) \quad$ Opening angle

0.5

$20^{\circ}$

10

$45^{\circ}$

17.1

$4 \pi$

2.15

$2 \pi$

40

30 


\section{Experimental Results}

A remarkable series of complex flares appeared in early August 1972, in particular on August 2, 4 and 7.

We observed these events in X-rays, but the time resolution (41 s) did not permit a fine time analysis. However the use of a satellite with a very eccentric orbit pointed at the Sun allowed us to follow the large scale evolution of the $\mathrm{X}$ - and gamma-radiation for all the events. Since the observations took place when the satellite was out of the magnetosphere, an increase in the background count rate was observed on all the detectors when the solar charged particles arrived near the Earth. One exception was the August 2 events, which will be analyzed first. In this case no contamination from these particles was observed.

(a) AUGUST 2 EVENTS

(i) Description of The Events

(a) First event. This event begins at 310 and shows a maximum at 330 . This large, early event is associated with a type 1B burst from the Mac Math region 11976 located at $13^{\circ} \mathrm{N}$ and $35^{\circ}-37^{\circ} \mathrm{E}$.

The SGL $1 \mathrm{X}$-ray spectrometer recorded the beginning of the event at 31120 , with the first maximum $\left(\sim 1\right.$ photon $\left.\mathrm{cm}^{-2} \mathrm{~s}^{-1} \mathrm{keV}^{-1}\right)$ at 330 in the energy range $38-77 \mathrm{keV}$. For this energy range a less pronounced secondary maximum $\left(\sim 0.5\right.$ photons $\mathrm{cm}^{-2}$ $\mathrm{s}^{-1} \mathrm{keV}^{-1}$ ) appeared at 40351 .

The decreasing time of this event is about $55 \mathrm{~min}$ and the total duration is 143 . (Figure 1).

The radio measurements we used were made at the Manila Observatory between 606 and $8800 \mathrm{MHz}$ (Castelli et al., 1973). High frequencies time profiles particularly at 8800,4995 and $2695 \mathrm{MHz}$, coincide well with the X-ray measurements. The second radio maximum ( 400) can be seen to be higher than the first at 4995 and $2695 \mathrm{M} \mathrm{Hz}$.

This radio burst has the usual characteristics of a proton flare burst (Castelli et al., 1973):

- slow rise to maximum, long duration;

- values greater than $1000 \mathrm{fu}$ at $\lambda=3 \mathrm{~cm}$;

- intense meter wavelength emission;

- typical U-shape of the frequency spectrum at the time of the 2 maxima (Figure 2).

In spite of these characteristics, the Signe 1 experiment did not measure any gamma emission in the energy range $0.35-3.9 \mathrm{MeV}$.

An X-ray spectrum corrected for detector effects can be obtained from the experimental data using a Monte-Carlo program (Bui-Van et al., 1973). This spectrum has the form $A E^{-\alpha}$ with $A=6.3 \times 10^{8}$ photons $\mathrm{cm}^{-2} \mathrm{~s}^{-1} \mathrm{keV}^{-1}$ and $\alpha=4.5$.

Knowing this spectrum one can deduce the energy associated with the electron component using the method by Brown (1972). For electrons with energy $E_{\mathrm{e}}>10 \mathrm{keV}$, an energy of $\sim 10^{30}$ ergs is obtained in the impulsive injection model and $5 \times 10^{29} \mathrm{ergs} \mathrm{s}^{-1}$ 


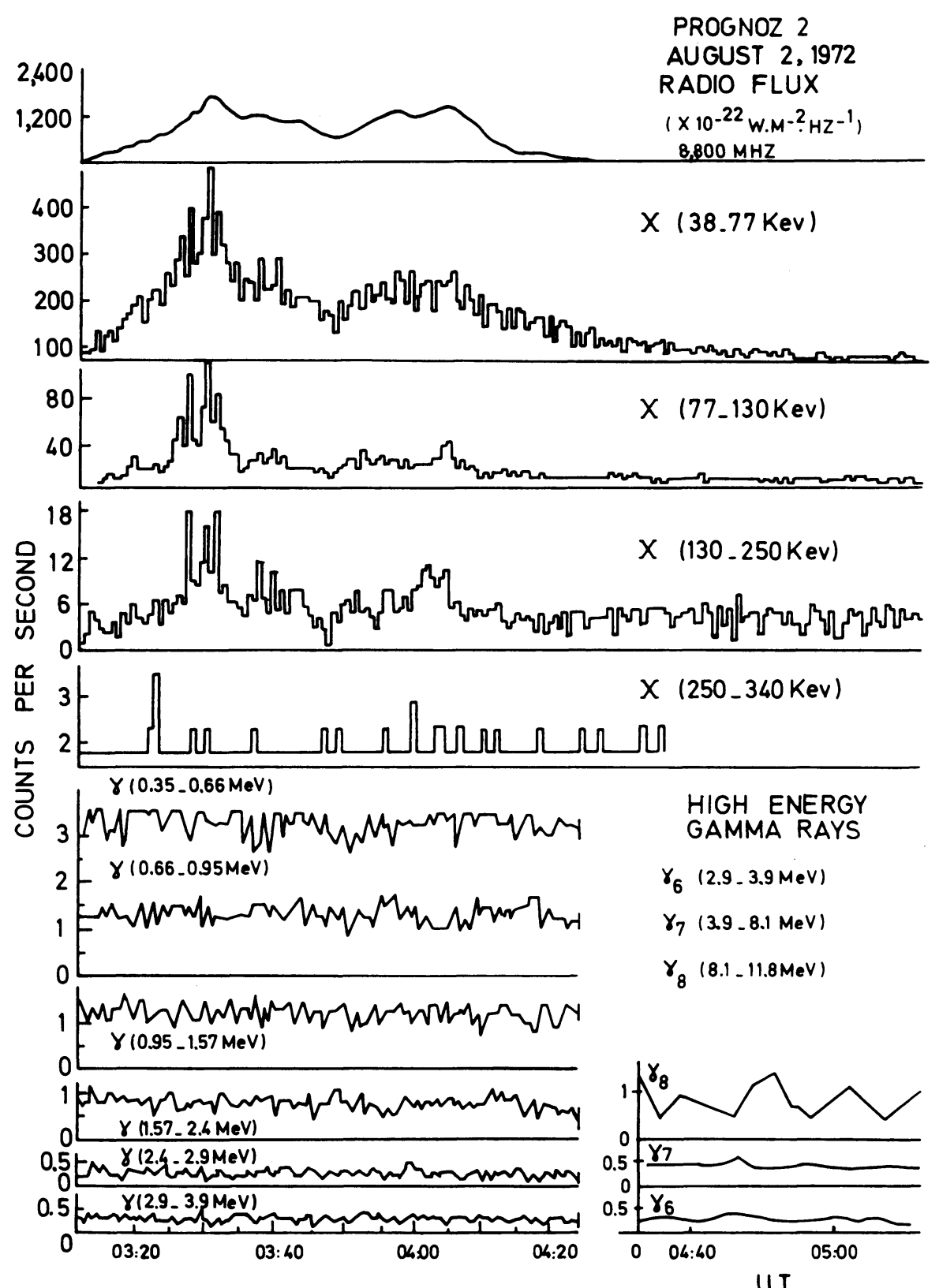

Fig. 1. Time profile of the X-and $\gamma$-ray measurements of the SGL 1 and Signe 1 experiments at 0300 UT in 1972, August 2. 


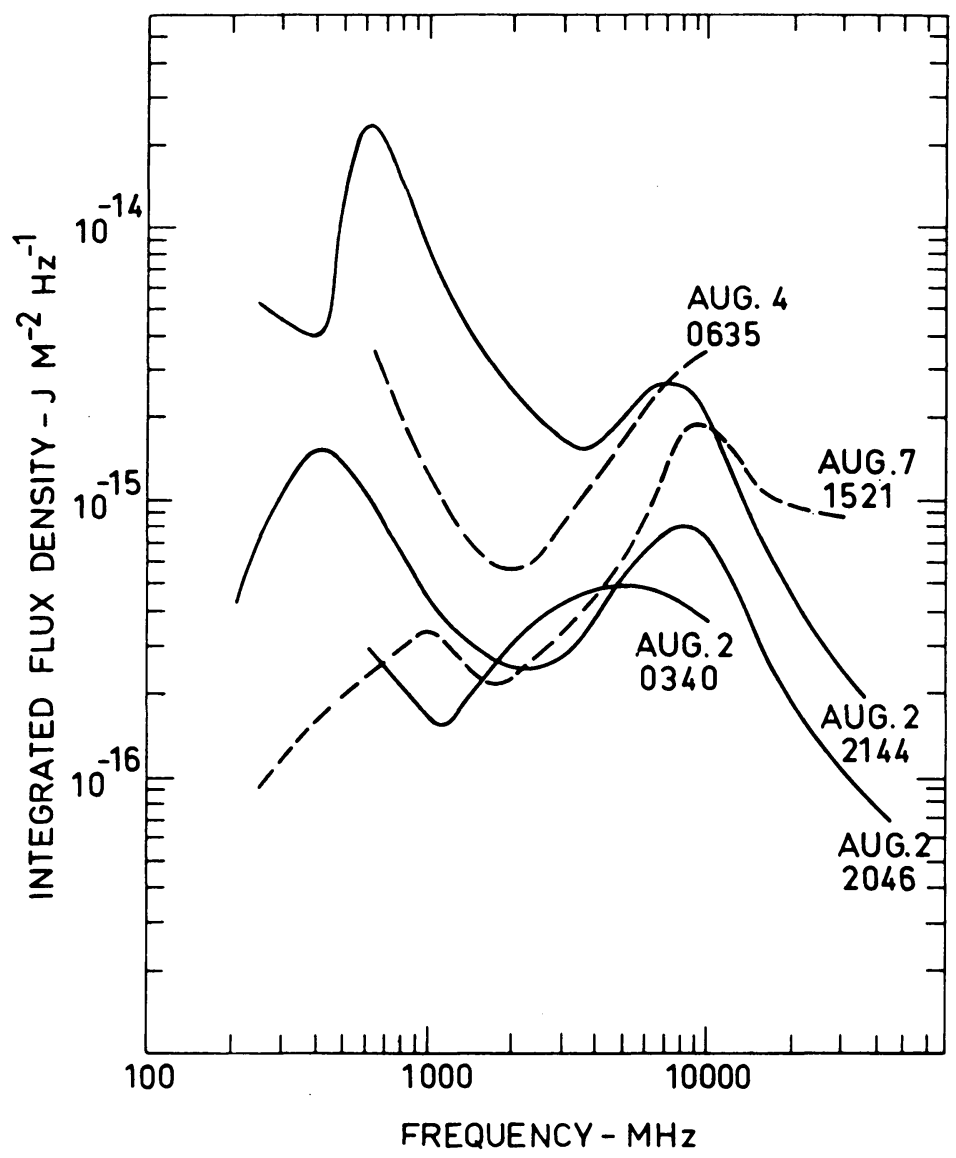

Fig. 2. Integrated flux density for proton associated bursts of August 1972. Curves derived from Sagamore Hill and Manila Data.

in the continuous injection model. These values, as has already been observed several times, are well above the energy calculated from the radio fluxes $\left(4.7 \times 10^{24}\right.$ erg in the range $600-8800 \mathrm{MHz}$ ).

( $\beta$ ) Second event. This very brilliant, impulsive Type $1 \mathrm{~B}$ flare was located at $15^{\circ} \mathrm{N}$ and $25-26^{\circ} \mathrm{E}$.

This event, observed in X-rays by our experiment and also by OSO 7 and TD 1 (Datlowe and Peterson, 1973; Van Beek et al., 1973), was short. In the 33-77 keV band the X-ray emission appears at 183818 and lasts about $8 \mathrm{~min}$, the maximum, at 1840 , is 0.77 photons $\mathrm{cm}^{2} \mathrm{~s}^{-1} \mathrm{keV}^{-1}$. At higher energies, the $\mathrm{X}$-ray emission is much shorter, about $41 \mathrm{~s}$ (Figure 3).

During the event the microwave spectrum was steeply rising to high frequencies which may indicate a low source height. At 1840 , about one minute after the maxi- 


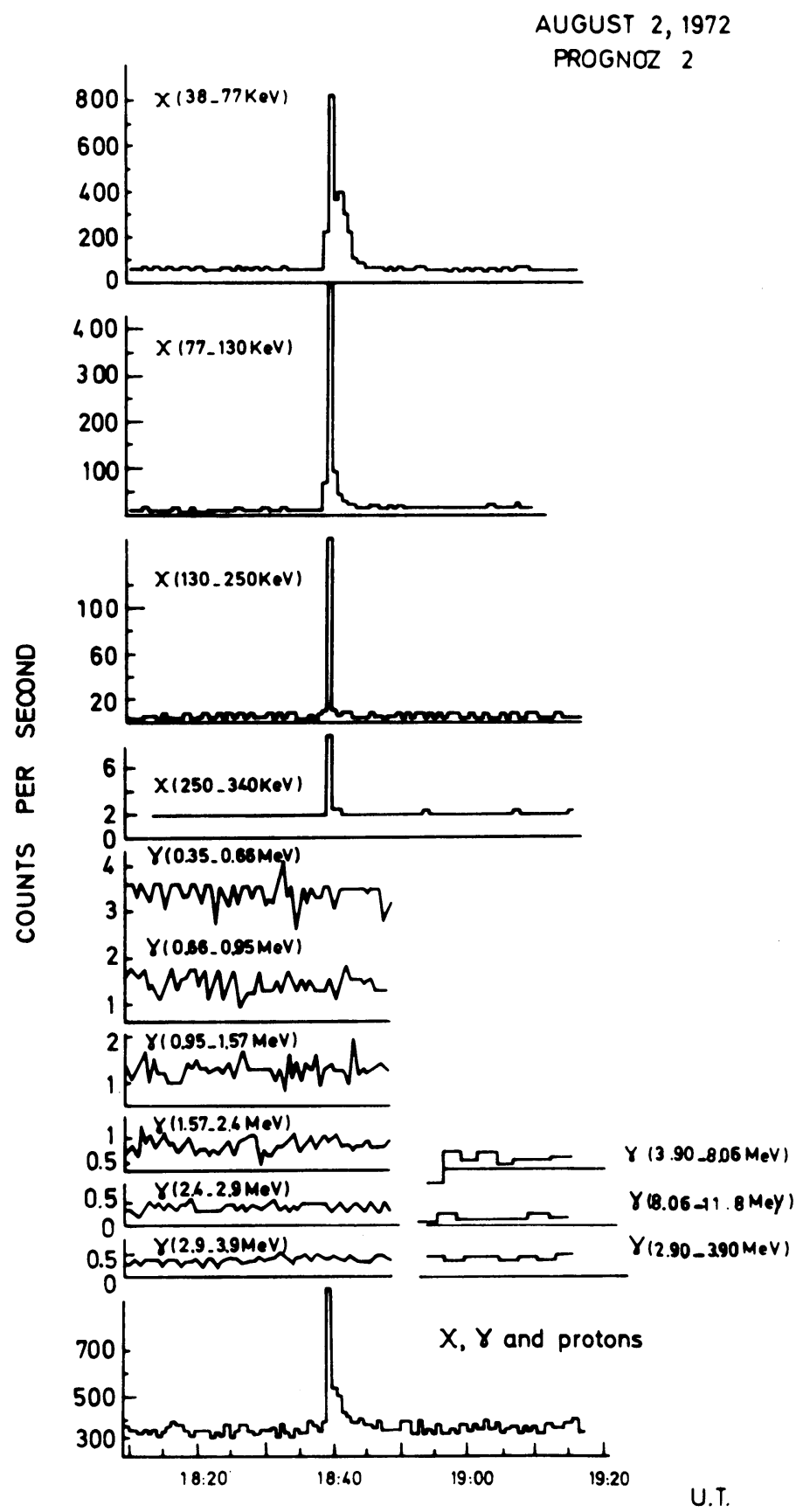

Fig. 3. The event of 1972, August 2, 1840 UT. 
mum, a rapid decrease of the flux around $35 \mathrm{GHz}$ was observed. This decrease coincided with the end of the $3825 \AA$ flash (Zirin and Tanaka, 1973).

Comparisons at optical $(3835 \AA), \mathrm{X}$ - and radio frequencies are given by Zirin and Tanaka (1973) and their conclusion is that the thick target X-ray emission model is more consistent than the thin target model for this impulsive flare.

Using our Monte Carlo program, we have found the incident photon spectrum. At the time of maximum it has the form $A E^{-\alpha}$ with $\alpha=3.7$ and $A=1 \times 10^{7}$ photons $\mathrm{cm}^{-2} \mathrm{~s}^{-1} \mathrm{keV}^{-1}$. These values are in good agreement with those of OSO 7 (Datlowe and Peterson, 1973). The energy dissipated by the electrons in collisions has been computed using Brown's method (Brown, 1972). For the thick target model which applies best to this event, as Zirin and Tanaka (1973) have noted the energy involved at the time of the maximum is about $3 \times 10^{29} \mathrm{erg} \mathrm{s}^{-1}$ for electrons above $10 \mathrm{keV}$.

During this event no gamma emission was observed.

( $\gamma$ ) Third event. This event is associated with a type 1B flare from the MacMath region $11976,13^{\circ} \mathrm{N}, 26-28^{\circ} \mathrm{E}$ and is the most structured of all the August $2 \mathrm{X}$-ray events. It is, however, similar to the $\mathbf{0 3} 10$ flare is some ways: it is a long-lived, slowly rising flare. The characteristics of this flare are already given by Zirin and Tanaka (1973): reached maximum at about 2005 and gave a modest hard X-ray burst; at 2020 there was a new increase in area and brightness. The hard X-ray flux increased, and at $8800 \mathrm{MHz}$ a large flux (6600 fu) was observed. The $\mathrm{H} \alpha$ front spread steadily to a maximum at 2050 UT. At 2140 the highest radio and X-ray flux peak can be noticed.

The entire event was observed by our X-ray detectors (Figure 4). For the first part of the event, OSO 7 could not give results because the satellite was in the Earth's shadow between about 2030 and 2110 . However, during the period from 2110 to 2200 the second part of the event was observed by this satellite and a large continuum was reported up to $600 \mathrm{keV}$. Unfortunately at the time of this second large maximum in X-rays, our gamma ray detector was in a calibration mode during which the anticoincidence was not working. Nevertheless it seems that an increase in the $\Delta E_{9}$ and $\Delta E_{10}$ channels appeared at about 2140 . But since these are the only data before the change in operating mode, no conclusive result is possible for this part of this event.

So we will concentrate on the first part of the event at 2040. Several bursts, particularly in the ranges $38-77 \mathrm{keV}$ and $77-130 \mathrm{keV}$ can be noted (Figure 5). This type of phenomenon can also be found in the August 7 events. The maximum for this event takes place at 204636 in the $38-77 \mathrm{keV}$ channel. At the time of the maximum the $\mathrm{X}$-ray spectrum has the following form: $8.10^{6} E^{-3.3 \pm 0.3}$ photons $\mathrm{cm}^{-2} \mathrm{~s}^{-1} \mathrm{keV}^{-1}$. The calculations, again using the method developed by Brown (1972), give values for the electron energy of $2 \times 10^{27} \mathrm{erg} \mathrm{s}^{-1}$ for $E_{\mathrm{e}}>40 \mathrm{keV}$ and $10^{33}$ electrons $^{-1}$ for $E_{\mathrm{e}}>100 \mathrm{keV}$.

It is interesting to note that during this first part of the event, at about 2045 a very high increase in the gamma-ray flux above $350 \mathrm{keV}$ (Figures 4 and 5) was observed. Figure 5 also shows the variation in radio flux at $8800 \mathrm{MHz}$. The good agreement 

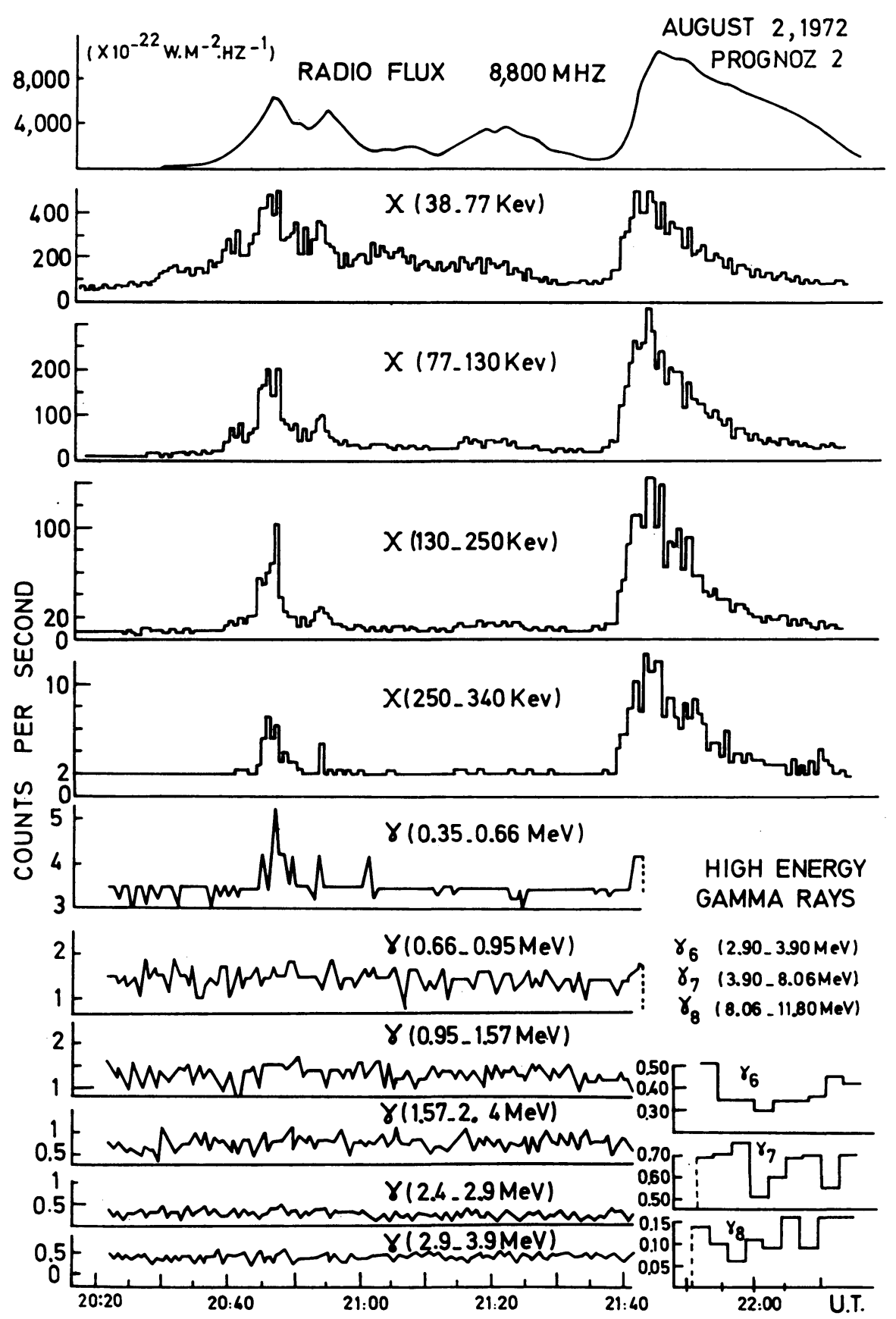

Fig. 4. Time profiles of the August 2, events 2040 and 2140 UT. 
between the time variations of the count rate observed in the $\Delta E_{9}$ channel and those of the radio and $\mathrm{X}$-ray fluxes beyond $70 \mathrm{keV}$ is evident. In addition, the radio spectrum can be seen to show the same characteristics as that of the 330 event (Figure 2). The U-shape of this spectrum is often taken to indicate the presence of charged particles.

AUGUST, 2,1972

PROGNOZ 2

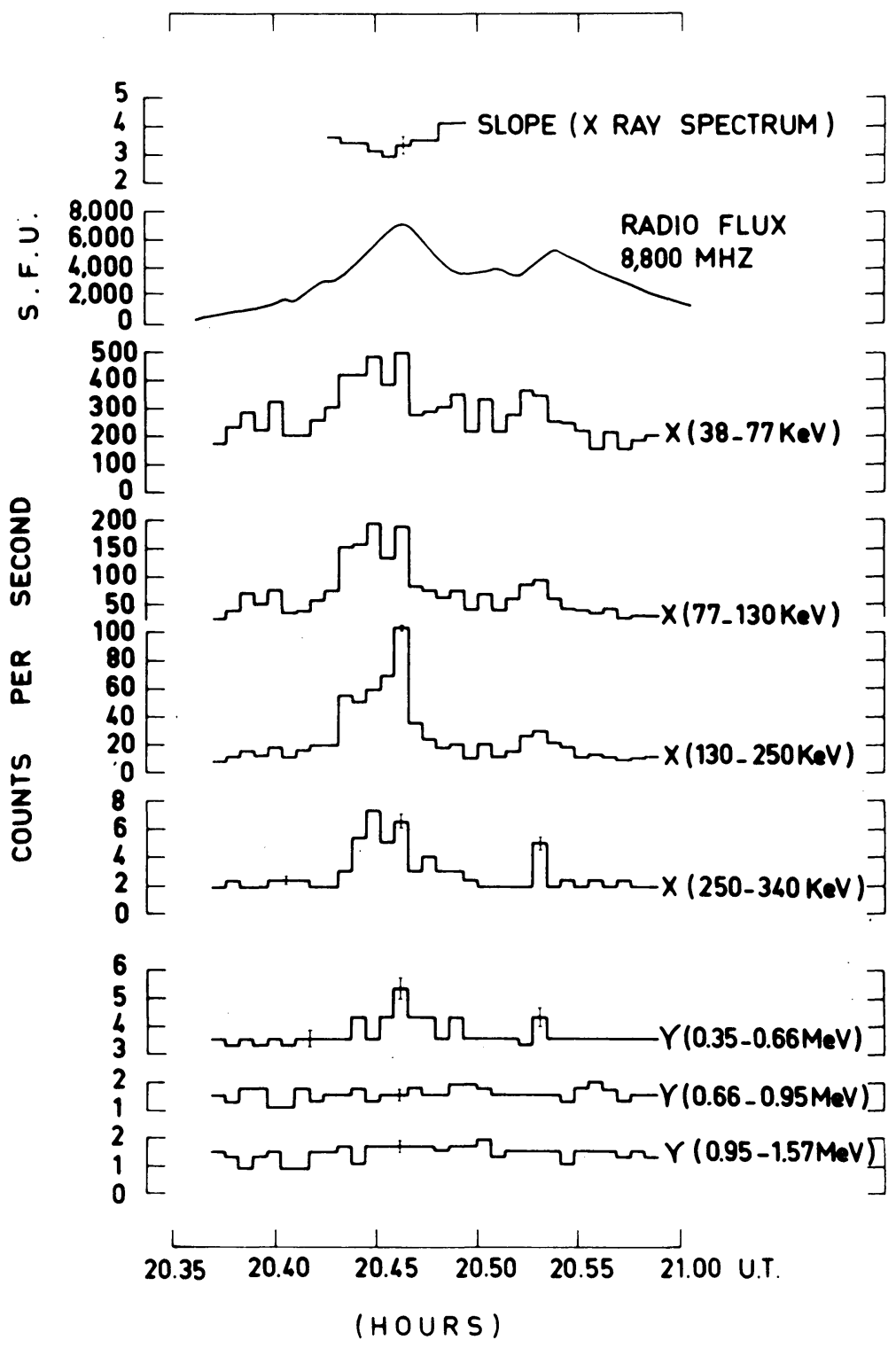

Fig. 5. A detailed time profile of the 2040 August 2 event. 
In order to interpret the flux increase in the $\Delta E_{9}$ channel and to determine whether this flux increase could be due in part to the presence of a line a $0.511 \mathrm{MeV}$, it is necessary to calculate the contribution of the continuum in the $\Delta E_{9}$ channel. We assume that the spectrum is a power law and that it can be extrapolated to higher energy.

(ii) POSSIBILITY OF A CONTRIBUTION OF THE $511 \mathrm{keV}$ LINE

The X-ray spectrum calculated has the form $8 \times 10^{6} E^{-3.3 \pm 0.3}$ photons $\mathrm{cm}^{-2} \mathrm{~s}^{-1}$ $\mathrm{keV}^{-1}$. The error in the exponent is calculated assuming a possible deviation of $3 \sigma$ in the experimental values obtained by the SGL 1 detector. Using this spectrum, we estimate the increase we would have had in the $\Delta E_{9}$ channel if the event had included only continuum. This increase is only detectable in the first channel $\left(\Delta E_{9}\right)$, but it is not enough to explain the increase observed. Table II gives the $41 \mathrm{~s}$ count rate values obtained in the $\Delta E_{9}$ and $\Delta E_{10}$ channels at the time of the maximum:

TABLE II

Counts observed during $41 \mathrm{~s}$ at the time of maximum intensity

$\begin{array}{lcccc}\begin{array}{l}\text { Energy } \\ \text { channel }\end{array} & \begin{array}{l}\text { Observed } \\ \text { counts }\end{array} & \text { Background } & \begin{array}{l}\text { Continuum contribu- } \\ \text { tion (of solar origin) }\end{array} & \begin{array}{l}\text { Possible } 0.5 \mathrm{MeV} \\ \text { line contribution }\end{array} \\ \Delta E_{9} & 237 & 155 & 24 & 58 \\ \Delta E_{10} & 56 & 56 & 5 & -\end{array}$

While this table shows a significant contribution which could be attributed to the $511 \mathrm{keV}$ line, it is necessary to take into account the errors in determining the continuum spectrum : specifically the continuum contribution in $\Delta E_{9}$ is $24 \pm 13$ cts (41 s) ${ }^{-1}$.

For a total detection efficiency of $33 \%$ the efficiency in the channel $\Delta E_{9}$ is $14 \%$, so the excess observed in this channel leads to a flux associated with the $511 \mathrm{keV}$ line which is:

$$
\phi_{0.511}=0.6 \pm 0.5 \text { photons } \mathrm{cm}^{-2} \mathrm{~s}^{-1} \text {. }
$$

Using the calculations of Ramaty and Lingenfelter (1973) which give a relation between the $511 \mathrm{keV}$ and $2.23 \mathrm{MeV}$ fluxes (Figures 6, 7) we can estimate the $2.23 \mathrm{MeV}$ line contribution in our detector if we know its sensitivity to this line.

The Table III gives the efficiencies of various energy channels for detecting $2.23 \mathrm{MeV}$ gamma photons.

TABLE III

Efficiencies of the various channels for $2.23 \mathrm{MeV}$ photons

\begin{tabular}{lcc}
\hline Energy channel & $\Delta E(\mathrm{keV})$ & Efficiency \% \\
$\Delta E_{9}$ & $0.4-0.7$ & 1.6 \\
$\Delta E_{10}$ & $0.7-1$ & 1.7 \\
$\Delta E_{11}$ & $1-1.6$ & 3.4 \\
$\Delta E_{12}$ & $1.6-2.4$ & 7.1 \\
$\Delta E_{1: 3}$ & $2.4-2.9$ & 0.6
\end{tabular}




The sensitivity of our detector in the $\Delta E_{12}$ channel where the efficiency is greatest, is 0.15 photons $\mathrm{cm}^{-2} \mathrm{~s}^{-1}$ at $2.23 \mathrm{MeV}$ at the $1 \sigma$ level and 0.33 photons $\mathrm{cm}^{-2} \mathrm{~s}^{-1}$ at the $2 \sigma$ level for $41 \mathrm{~s}$.

The calculation of Wang and Ramaty (1974) enables us to specify the expected fluxes at $2.23 \mathrm{MeV}$ for different rigidities in both thick and thin target models, knowing the $511 \mathrm{keV}$ flux. The values are given in Table IV.

TABLE IV

Expected photons $\mathrm{cm}^{-2} \mathrm{~s}^{-1}$ at $2.23 \mathrm{MeV}$

\begin{tabular}{|c|c|c|c|c|c|c|}
\hline \multirow{3}{*}{$\begin{array}{l}\text { Proton } \\
\text { rigidity }\end{array}$} & \multicolumn{3}{|c|}{ Thick target model } & \multicolumn{3}{|c|}{ Thin target model } \\
\hline & \multicolumn{6}{|c|}{$\phi 0.511 \mathrm{MeV}$ (photons $\mathrm{cm}^{-2} \mathrm{~s}^{-1} \mathrm{keV}^{-1}$ ) } \\
\hline & 0.1 & 0.6 & 1.1 & 0.1 & 0.6 & 1.1 \\
\hline $40 \mathrm{MV}$ & 0.08 & 0.4 & 0.8 & 0.05 & 0.3 & 0.5 \\
\hline $50 \mathrm{MV}$ & 0.1 & 0.6 & 1.2 & 0.1 & 0.6 & 1.1 \\
\hline $100 \mathrm{MV}$ & 0.18 & 1 & 1.9 & 0.3 & 1.6 & 2.8 \\
\hline
\end{tabular}

Under these conditions, the absence of a $2.23 \mathrm{MeV}$ line contribution in the $\Delta E_{12}$ channel (where efficiency at $2.23 \mathrm{MeV}$ is highest) makes it possible to define an upper limit for the gamma flux value at $0.5 \mathrm{MeV}$, assuming that Wang and Ramaty's model does indeed represent the gamma line emission processes.

The upper limits to the photon flux at $0.5 \mathrm{MeV}$ are then:

$\begin{array}{rll}\begin{array}{l}\text { Proton } \\ \text { rigidity }\end{array} & \text { Thick-target } & \text { Thin-target } \\ & \\ 40 \mathrm{MV} & 0.44 \text { photons } \mathrm{cm}^{-2} \mathrm{~s}^{-1} & 0.66 \text { photons } \mathrm{cm}^{-2} \mathrm{~s}^{-1} \\ 50 \mathrm{MV} & 0.28 \text { photons } \mathrm{cm}^{-2} \mathrm{~s}^{-1} & 0.33 \text { photons } \mathrm{cm}^{-2} \mathrm{~s}^{-1} \\ 100 \mathrm{MV} & 0.18 \text { photons } \mathrm{cm}^{-2} \mathrm{~s}^{-1} & 0.12 \text { photons } \mathrm{cm}^{-2} \mathrm{~s}^{1}\end{array}$

We estimate next the characteristic rigidity of this event in order to give a more accurate upper limit.

(a) Determination of the event's characteristic rigidity. The rigidity can be estimated using measurements from Explorer 41 (Bostrom et al., 1972) but for the August 2 event there is a problem: the flare responsible for the proton emission is located to the east on the Sun. Since the lateral diffusion of these protons is low compared to the diffusion along the magnetic field line, it is impossible to attribute the proton flux increase to any particular August 2 event; as we have seen, all these events can be responsible for proton emission. The Explorer 41 data however, indicate a plateau at 1200 UT August 3. This configuration being typical of the events occurring to the east on 
the Sun. We have therefore determined the characteristic rigidity using the Explorer 41 data, assuming that this rigidity was conserved in the scattering.

The flux values measured under these conditions will necessarily be lower than those at the Sun. The observed fluxes were as follows:

$\begin{array}{ll}\text { Proton energy } E & \text { Integral proton flux at the Earth } J(-E) \\ & 500 \text { protons } \mathrm{cm}^{-2} \mathrm{~s}^{-1} \\ 10 \mathrm{MeV} & 37 \text { protons } \mathrm{cm}^{-2} \mathrm{~s}^{-1} \\ -30 \mathrm{MeV} & 12.5 \text { protons } \mathrm{cm}^{-2} \mathrm{~s}^{-1}\end{array}$

From these values one can deduce the proton density in the interplanetary medium $U(P)$, since, if this density is put into the form $U(P) \simeq \exp \left(-P / P_{0}\right)$ then

$$
U(>P)=J(>P) \cdot \frac{m c}{e} \cdot\left(P+P_{0}\right)^{-1} \text { with } \frac{m c}{e}=3.12 \times 10^{-8}
$$

Under these conditions and with the above mentioned reservations the characteristic rigidity can be estimated at between 40 and $50 \mathrm{MV}$.

( $\beta$ ) Number of protons emitted in the event assuming a gamma-ray line emission. The estimate of the number of protons at the Sun in the thick target model are obtained for an average rigidity of $45 \mathrm{MV}$ and for $511 \mathrm{keV}$ fluxes of 0.1 photons $\mathrm{cm}^{-2} \mathrm{~s}^{-1}$ and 0.35 photons $\mathrm{cm}^{-2} \mathrm{~s}^{-1}$. In this case as the event lasts $41 \mathrm{~s}$, the total number of protons according to Figure 7 lies between $5 \times 10^{33}$ and $2 \times 10^{34}$ protons.

These values can be compared to that deduced from observations made at the Earth. But we have pointed out that the main problem lies in the low value of proton fluxes measured at the earth when emitted east of the Sun. However it is possible to give an approximation of these fluxes ( $>10 \mathrm{MeV}$ ) by using the curve of Straka (1970) (Figure 8 ). In order to do this, we have determined the energy from radio observa-

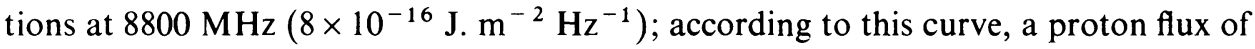
about $600 \mathrm{p} \mathrm{cm}^{-2} \mathrm{~s}^{-1} \mathrm{sr}^{-1}$ results, or 15 times the value of the fluxes measured. Using this proton flux and a volume occupied by the particles in interplanetary space of $10^{39} \mathrm{~cm}^{3}$ (Ramaty and Lingenfelter, 1973), the number of protons is equal to $2.6 \times 10^{34}$.

( $\gamma)$ Ambient density of the solar atmosphere. In the thin target model taking the $0.511 \mathrm{MeV}$ line flux between 0.1 and 0.45 photons $\mathrm{cm}^{-2} \mathrm{~s}^{-1}$ one obtains for $n N$ (Figure 6):

$$
7 \times 10^{45}<n N<3 \times 10^{46} .
$$

Thus, taking the value derived from measurements at the Earth for the number of protons, the number density of the ambient solar material $\left(\mathrm{cm}^{-3}\right)$ becomes:

$$
3 \times 10^{11}<n<1 \times 10^{12} .
$$




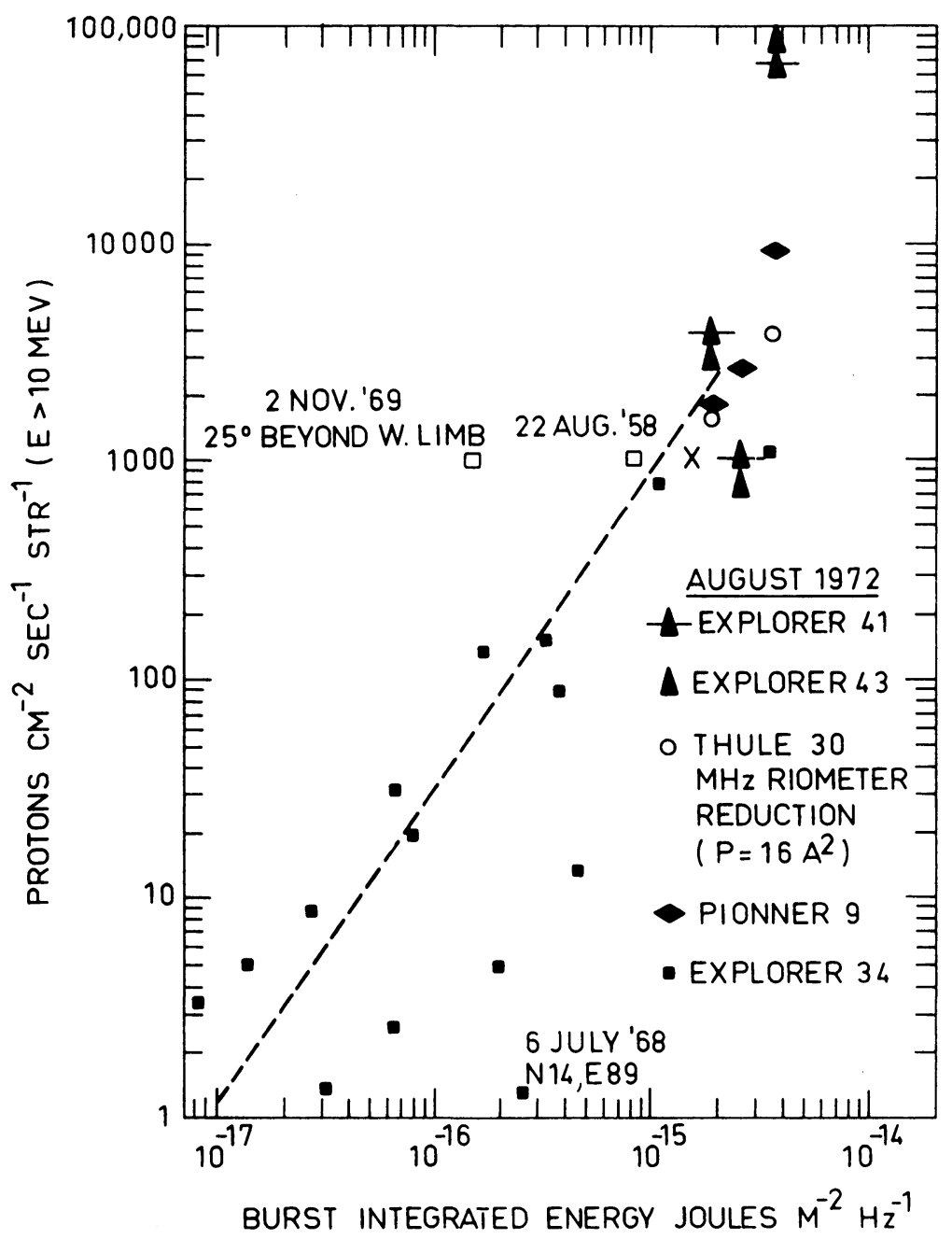

Fig. 8. Burst integrated energy at $8800 \mathrm{MHz}$ vs proton flux.

( $\delta)$ Energy involved during the flare. First we consider the thick-target model. Assuming that the proton population has a spectrum with the form $N(P)=P_{0}^{-1} \exp \left(-P / P_{0}\right)$, the average proton energy is $P_{0}^{2} / M c^{2}$ or $3.4 \times 10^{-6} \mathrm{erg}$. The total energy involved is then:

$$
1.7 \times 10^{28} \text { ergs }<\mathrm{W}_{\mathrm{T}}<6.8 \times 10^{28} \mathrm{ergs}
$$

In order to find the energy involved in the thin target model, we compute the energy $W$ dissipated per unit time by a proton, in a medium having a density of $1 \mathrm{~cm}^{-3}$ (Ramaty and Lingenfelter, 1973).

The results are presented in Table $\mathrm{V}$. Using the value $1.9 \times 10^{-18} \mathrm{erg} \mathrm{s}^{-1}$ for a rigidity of $45 \mathrm{MV}$ and the values of $n N$ previously calculated, we obtain the energy 
TABLE V

Energy dissipated by protons in the thin-target model

$\begin{array}{cl}\begin{array}{l}\text { Rigidity } \\ P_{0}(\mathrm{MV})\end{array} & \begin{array}{l}\text { Energy dissipated } \\ \mathrm{W} \times 10^{-18} \mathrm{erg} \mathrm{s}^{-1}\end{array} \\ 20 & 2 \\ 30 & 2 \\ 40 & 1.9 \\ 60 & 1.8 \\ 80 & 1.6 \\ 100 & 1.5 \\ 120 & 1.4 \\ 200 & 1.2 \\ 300 & 1.1\end{array}$

involved, $E$, for an event lasting $41 \mathrm{~s}$ :

$$
5 \times 10^{29} \text { ergs }<E<2 \times 10^{30} \text { ergs } .
$$

(b) AUGUST 7 EVENT

(i) Description of The Event

In the MacMath region 11976 with which the events of August 2 and 4 have already been associated, an event appeared on August 7. Figure 9 shows recording from RS 1, SGL 1, and Signe 1 detectors as well as the proton detector data for the burst period. For purpose of comparison, the same figure shows radio fluxes at a frequency of $15400 \mathrm{MHz}$ (Castelli et al., 1973), as well as the periods when type III and type II bursts were observed (Lincoln et al., 1972). From Figure 9 the low energy X-ray burst (curves 1, 2 and 3) can be seen to begin shortly before the burst appearing at higher energies (curves 6,7 and 8); the highest energy component reaches a maximum towards $1521 \mathrm{UT}$, and then drops very rapidly. The X-ray time profile, particularly at high energies, coincides fairly well with the shape of the microwave radio burst. Figure 10 shows the time correlation between our data, radio flux measurements and TD1 and Intercosmos 7 experiments where the time resolution was better (Van Beek et al., 1973, Valnicek et al., 1973). The two types of radiation typically show a 'step' profile in time with intermediary maxima 1516, 151730, 1519 UT (Figures 9 and 10 ). This is probably related to the intermediary maxima indicated above in the $\mathrm{X}$-ray and radio ranges.

The radio observation data in the frequency range 245 to $15400 \mathrm{MHz}$ (Castelli et al., 1973) indicate that the beginning of the radio burst may be situated at 1422 and the observable increase in frequencies 930 to $2800 \mathrm{MHz}$ begins at $1505 \mathrm{UT}$, simultaneously with an increase in $\mathrm{H} \alpha$ line intensity (Lincoln et al., 1972).

Beginning at 1519 UT a white light burst appears lasting 7 to 8 minutes from the moment of maximum intensity in the radio spectrum (Castelli et al., 1973). A type II radio burst also appears which seems to begin at about 1521 UT and which lasts 


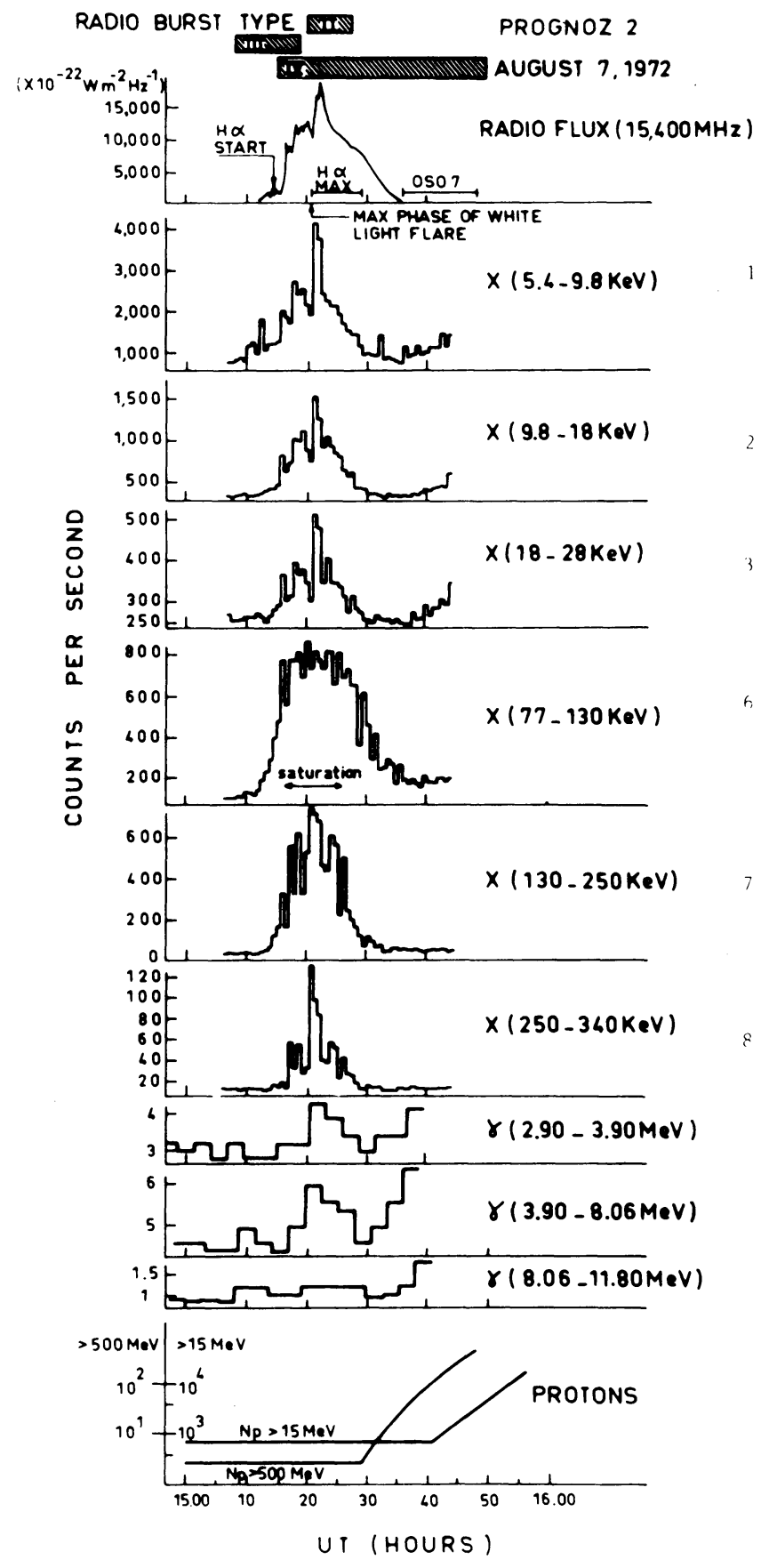

Fig. 9. Time profiles of the X-ray, $/$-ray and proton measurements in the August 7 event. 
till 1535 UT (Dodge, 1973). At 152130 a flux maximum in the hard X-ray photon flux is noted almost simultaneous with an increase in the count rate in the range 2.9-7.8 MeV. The gamma burst lasts about 8 to $10 \mathrm{~min}$.



Fig. 10. A detailed time profile of X-ray measurements in the August 7 event. 
Since the X-ray measurements have a time resolution of $41 \mathrm{~s}$ it is not possible to show an accurate time correlation in the development of the photon fluxes for these two energy ranges. Nonetheless, the X- and gamma-events end at about 1527 UT, shortly before the high-energy protons appear.

The increase in intensity of these protons $\left(E_{\mathrm{p}} \geqslant 500 \mathrm{MeV}\right)$ begins at $1529-1530$, while the low energy charged particles $\left(1 \mathrm{MeV}<E_{\mathrm{p}}<200 \mathrm{MeV}\right)$ appear only at about 1535 UT. Under these conditions the excess of the gamma ray fluxes between 1522 and 1530 cannot be interpreted as local production due to the arrival of protons. In addition we note that the arrival of protons coincides well with a very clear $\gamma$-ray flux increase which can be explained by local $\gamma$-ray production.

Chupp et al. (1973b) have already shown evidence for the $511 \mathrm{keV}, 2.23 \mathrm{MeV}$, 4.43 MeV, and 6.1 MeV gamma lines related to positron annihilation, formation of deuterium, and excited states of $\mathrm{C}^{12}$ and $\mathrm{O}^{16}$ nuclei in these events. In our observations of this event, the spectral characteristics of the gamma-radiation were difficult to obtain due to the limited number of channels and to the measurement method. Nevertheless we shall try to analyze these data taking into account the contribution of the excited states of oxygen and carbon nuclei.

But first we shall comment on the time correlation in the different wavelength ranges. One of the most interesting results of the observational data is the correlation between type II radio bursts, and the arrival and time behavior of the energetic protons recorded over the gamma radiation which they produce in the flare region.

The radio bursts of this type usually appearing after large events result from the formation of a shock wave. For example in the August 4 event the type II radio burst at frequencies of $4824 \mathrm{MHz}$ was observed between 0629 and 063305 (Castelli et al., 1973), i.e. during the period of the gamma-burst. We can suppose at much higher frequencies this burst began a little earlier. However, a complex image of radio disturbances for this whole period makes it difficult to know the exact moment of the beginning of the type II burst.

In the August 7 event, the image of the correlation is clearer; the type II radio burst began at 1519 (according to data from different stations this moment can be determined to within $+1 \mathrm{~min},-0.3 \mathrm{~min}$ ) (Lincoln et al., 1972) and lasts until 1537. The gamma burst under observation began at 1522 and continued until 1530. The beginning of the burst is determined to within $\pm 1 \mathrm{~min}$. Thus we can consider that between the start of the type II radio burst at 1519 and of the gamma burst at 1522, there was a certain time delay $t \simeq 10^{2} \mathrm{~s}$ which may indicate that the maximum proton flux density does not appear immediately after the shock wave formation.

Concerning time correlations between the event recorded in X-and $\gamma$-rays, we can note that the $\mathrm{X}$ - and $\gamma$-ray flux increases are simultaneous to within our time measurements errors. But when the $X$ event lasts only about 2 min the $\gamma$-ray event extends over on period of about 8 to $10 \mathrm{~min}$. This lack of correlation in the length of the 2 events is further evidence of a different origin for the X-rays (electron bremsstrahlung) and $\gamma$-ray fluxes (solar atmosphere proton interactions). 
(ii) Evaluation of a Possible Continuum Contribution above $3 \mathrm{MeV}$

As we have just remarked time correlations between $X$ - and $\gamma$-ray events seem to indicate a different origin for these emissions.

In spite of this argument, we have attempted to calculate the contribution of a continuum in channels $\Delta E_{14}, \Delta E_{15}, \Delta E_{16}$ taking into account the low energy measurements $(<340 \mathrm{keV})$ given by SGL 1 detector. So this estimate is very approximate because we have no spectral information between $340 \mathrm{keV}$ and $3 \mathrm{MeV}$.

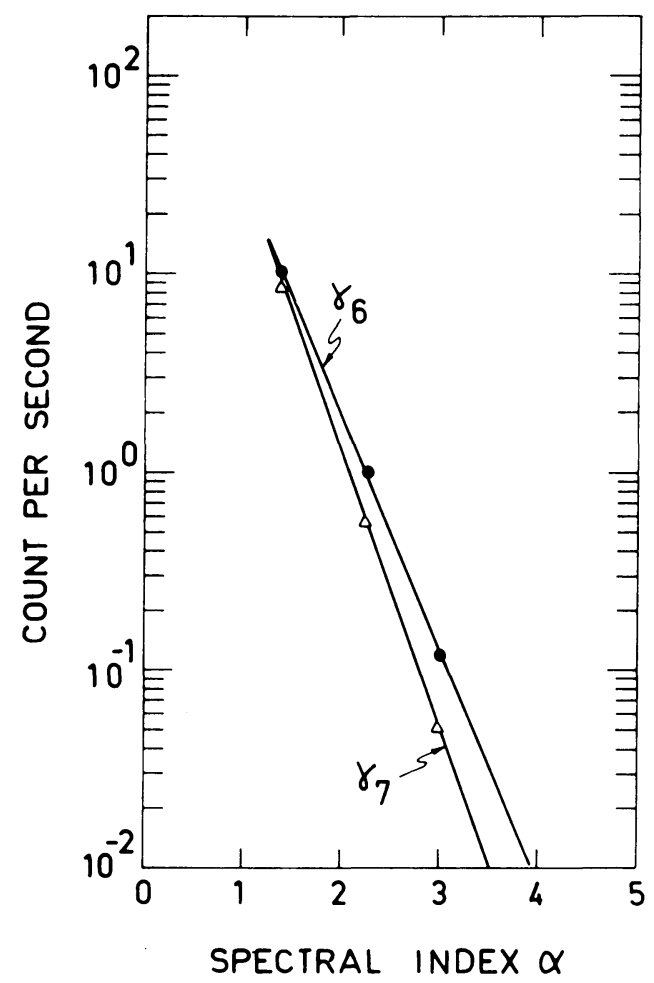

Fig. 11. Counting rate in $\Delta E_{14}$ and $\Delta E_{15}$ vs. photon spectrum index $\alpha$ (normalized to channel $250-340 \mathrm{keV})$.

We have used the Monte Carlo program to calculate the contribution of the continuum in $\Delta E_{14}, \Delta E_{15}$ for different slopes of this spectrum, the $\gamma$-ray spectrum being normalized to the value of the flux observed between 250 and $340 \mathrm{keV}$ (Figure 11). If we retain a spectrum in $E^{-3}$ which is rather close to that of the continuum for the August 4 event (Chupp et al., 1974 - private communication), we notice that the expected gamma contribution is negligible compared with the counts observed. It must also be pointed out that whenever the exponent of the spectrum is greater than 1, it leads to contributions in $\Delta E_{14}$ and $\Delta E_{15}$ which are in ratio always greater than 1; for example, for $\alpha=2.3, \Delta E_{14} / \Delta E_{15}=2$, and this ratio increases at higher energy while $\Delta E_{14} / \Delta E_{15}$ observed during the event is 0.6 (Figure 11 ). 
Let us further note that it is difficult to assume a spectrum of photons having a slope of less than 2 above $500 \mathrm{keV}$ because the resulting gamma photon flux above $500 \mathrm{keV}$, would cause an increase in the anticoincidence count rate, which would be significant. However, no such systematic increase during the event was observed.

None of these arguments constitutes a definitive proof as to the absence of significant continuum contribution. It nevertheless seems clear that if we take a spectrum above $400 \mathrm{keV}$ with a slope less than 2.5 , the total count rate observed cannot be due to the continuum, the best proof still being the ratio of the fluxes observed in $\Delta E_{15}$ and $\Delta E_{16}$.

Under these conditions, the presence of a contribution of monoenergetic gamma photons is reasonably possible. However, we can only give it as upper limit by supposing that the entire observed contribution is due to the presence of these lines. If a continuum exists, it can provide a contribution that is impossible to determine precisely, given the observational data at the time of the event.

\section{(iii) Evaluation of a Possible $\gamma$-Ray Line Contribution}

Calculations have been made under the assumption that only the 6.14 and $4.43 \mathrm{MeV}$ lines are excited (Ramaty and Lingenfelter 1973). In fact perhaps the actual situation at the Sun is much more complicated than it is supposed here.

Due to poor time resolution the length of the event cannot be given exactly but lies between 8 and $11 \mathrm{~min}$. Taking into account the detection efficiency for these two lines and using the Monte-Carlo program we have calculated the fluxes of 4.43 and 6.14 $\mathrm{MeV} \gamma$-ray lines to be 1.8 and 0.7 photon $\mathrm{cm}^{-2} \mathrm{~s}^{-1}$ respectively for a $\gamma$-ray burst lasting $8 \mathrm{~min}$.

We can try to check if these $\gamma$-ray line fluxes are in agreement with those measured by Chupp et al. (1973a) on OSO 7. But as these measurements are obtained later we have to consider the time evolution of the $2.23 \mathrm{MeV}$ flux to estimate what the $2.23 \mathrm{MeV}$ flux would have been at the moment of our measurements. For simplification we can choose a time evolution for the $2.23 \mathrm{MeV}$ flux given by $\exp \left[-\lambda\left(t-t_{0}\right)\right]$ with $\lambda=\tau_{\mathrm{c}}^{-1}+\tau_{\mathrm{d}}^{-1}$ where $\tau_{\mathrm{c}}$ is the capture time of neutrons on hydrogen and $\tau_{\mathrm{d}}$ the mean neutron lifetime (Reppin et al., 1973). In this case we neglect the dependence of $\phi$ on $\theta$ and $E_{\mathrm{n}}$ (Wang en Ramaty, 1974), ( $\theta$ is the angle between the Earth-Sun line and the vertical to the plane stratified medium; $E_{\mathrm{n}}$ is the neutron energy). The capture time $\tau_{\mathrm{c}}$ is $\sim 100 \mathrm{~s}$. for a density of the ambient solar atmosphere $n=10^{17} \mathrm{~cm}^{-3}$ if we use the expression $\tau_{\mathrm{c}}(\mathrm{s}) \simeq\left(1.5 \times 10^{19} / n\left(\mathrm{~cm}^{-3}\right)\right)$ (Wang and Ramaty, 1974).

The $2.2 \mathrm{MeV} \gamma$-ray line at the end of the neutron production is given by $\phi_{t 0}$ :

$$
\phi_{t 0}=\phi_{t} \exp \left[-\lambda\left(t-t_{0}\right)\right] \text {. }
$$

Since the radio and $\mathrm{X}$-ray measurements seem to indicate that the event ends at 1530 we may suppose that the neutron production also ends at this time. So if we take for $\phi_{t}$ the $2.23 \mathrm{MeV} \gamma$-ray flux measured by OSO 7 at about $1538\left(\phi_{t} \simeq 4.8 \times 10^{-2}\right.$ $\mathrm{cm}^{-2} \mathrm{~s}^{-1}$ ) we obtain for $\phi_{t 0} \sim 2$ photons $\mathrm{cm}^{-2} \mathrm{~s}^{-1}$. 
With these values of $\phi$ and a rigidity of $\sim 50 \mathrm{MV}$ for the event, the calculations of Ramaty et al. (1973) give a ratio of $\sim 3$ between the $\gamma$-ray lines at 2.2 and $4.4 \mathrm{MeV}$ for the thick target model. If we take into account the revised $\gamma$-ray fluxes at $2.23 \mathrm{MeV}$ (Wang and Ramaty, 1974), which are lower than the values already published by a factor $2-2.5$, the ratio $\phi_{2.2} / \phi_{4.4} \simeq 1.2$ to 1.5 for $50 \mathrm{MV}$ rigidity. In this case we have a reasonably good agreement between theoretical calculations and our measurements at the end of the event at about 1530 .

We shall now compare Ramaty's theoretical estimates with our experimental results in order to evaluate some of the basic parameters of the solar flare. But before that we need to determine the rigidity of the protons spectrum.

(a) Determination of the event's characteristic rigidity. This rigidity is defined as for the August 2 event using the measurements made by Bostrom et al. (1972). For the August 7 event we have the following values:

$$
\begin{aligned}
& J(>10 \mathrm{MeV})=4.2 \times 10^{4} p \mathrm{~cm}^{-2} \mathrm{~s}^{-1} \\
& J(>30 \mathrm{MeV})=4.56 \times 10^{3} \mathrm{~cm}^{-2} \mathrm{~s}^{-1} \\
& J(>60 \mathrm{MeV})=8.4 \times 10^{2} p \mathrm{~cm}^{-2} \mathrm{~s}^{-1}
\end{aligned}
$$

From Equation (7) the characteristic proton rigidity can be seen to be between 40 and $50 \mathrm{MV}$, which corresponds to densities of $U(>10 \mathrm{MeV})=7.24 \times 10^{-6} \mathrm{~cm}^{-3}$, $U(>30 \mathrm{MeV})=5 \times 10^{-7} \mathrm{~cm}^{-3}$, and $U(>60 \mathrm{MeV})=6.8 \times 10^{-8} \mathrm{~cm}^{-3}$, for an average characteristic rigidity of $45 \mathrm{MV}$. When curves $f(P)$ (Figure 12) are plotted, the values 40 and $50 \mathrm{MV}$ corresponding to the slopes of these curves do reflect the average value of $45 \mathrm{MV}$. The particle rigidity derived from these observations is thus included between 40 and $50 \mathrm{MV}$. The results based on this and using of Ramaty's and Lingenfelter's calculations appear below.

We have to note, however, that the following estimates depend strongly on the characteristics of the proton spectra. In particular, the high values of the number of protons in the thick-target model, the density of the region where the $\gamma$-photons are produced in the thin-target model, and the energies involved would be reduced by an order of magnitude if the rigidity reached $100 \mathrm{MV}$.

( $\beta$ ) Number of protons involved in the flare. According to Figure 7 we obtain the following photons fluxes normalized to one proton:

\begin{tabular}{lcc} 
Proton rigidity & $4.43 \mathrm{MeV}$ & $6.14 \mathrm{MeV}$ \\
\cline { 2 - 3 } $40 \mathrm{MV}$ & $3.3 \times 10^{-34}$ & $2.4 \times 10^{-34}$ \\
$50 \mathrm{MV}$ & $8.7 \times 10^{-34}$ & $5.7 \times 10^{-34}$
\end{tabular}

Since the total fluxes at $4.43 \mathrm{MeV}$ and $6.14 \mathrm{MeV}$ are respectively 883 photons $\mathrm{cm}^{-2}$ 




Fig. 12. Density of protons near the Earth vs rigidity for 2 characteristic rigidities in the 1972, August 7 event.

and 331 photons $\mathrm{cm}^{-2}$, from Ramaty's curve it is possible to estimate the number of protons involved in the event:

\begin{tabular}{llll} 
Proton rigidity & $4.43 \mathrm{MeV}$ & $6.14 \mathrm{MeV}$ & Average value \\
\hline $40 \mathrm{MV}$ & $2.7 \times 10^{36}$ & $1.4 \times 10^{36}$ & $2.0 \times 10^{36}$ \\
$50 \mathrm{MV}$ & $1.0 \times 10^{36}$ & $5.8 \times 10^{35}$ & $8.0 \times 10^{35}$
\end{tabular}

From Figure 12 one can obtain the proton density in interplanetary space, and the proton flux at the Sun can be deduced:

$$
2.5 \times 10^{35}<N(P>0)<5.6 \times 10^{34} \text { for } 40 \mathrm{MV}<P_{0}<50 \mathrm{MV}
$$


This estimate is made on the assumption that the volume occupied by the particles in interplanetary space is a cone with a $30^{\circ}$ opening angle whose vertex is on the Sun (Ramaty and Lingenfelter, 1973). This volume is estimated to be $10^{39} \mathrm{~cm}^{3}$. These two determinations of the proton flux at the Sun are not in good agreement.

$(\gamma)$ Density in the solar atmosphere deduced from the thin target model. From Figure 6 we find the number of photons produced by one proton in a solar atmosphere having a density of $1 \mathrm{~cm}^{-3}$.

\begin{tabular}{lll}
\hline Proton rigidity & $4.43 \mathrm{MeV}$ & $6.14 \mathrm{MeV}$ \\
\hline $40 \mathrm{MV}$ & $9.4 \times 10^{-48}$ & $6.9 \times 10^{-48}$ \\
$50 \mathrm{MV}$ & $1.7 \times 10^{-47}$ & $1.2 \times 10^{-47}$
\end{tabular}

Since the photon fluxes measured are 1.8 photons $\mathrm{cm}^{-2} \mathrm{~s}^{-1}$ at $4.43 \mathrm{MeV}$ and 0.7 photons $\mathrm{cm}^{-2} \mathrm{~s}^{-1}$ at 6.14 , we can estimate the product $n N$ expressed in $\mathrm{cm}^{-3}$, i.e.

\begin{tabular}{lll}
\hline Proton rigidity & $4.43 \mathrm{MeV}$ & $6.14 \mathrm{MeV}$ \\
\hline $40 \mathrm{MV}$ & $1.9 \times 10^{47}$ & $1.0 \times 10^{47}$ \\
$50 \mathrm{MV}$ & $1.1 \times 10^{47}$ & $5.8 \times 10^{46}$ \\
\hline
\end{tabular}

The number of protons $N$ is obtained by estimates given above: $N=2.5 \times 10^{35}$ for $P_{0}=40 \mathrm{MV}$ and $5.6 \times 10^{34}$ for $P_{0}=50 \mathrm{MV}$. The density encountered by the protons at the Sun for the creation of measured photon fluxes is given in the following table:

\begin{tabular}{llll}
\hline Proton rigidity & $4.43 \mathrm{MeV}$ & $6.14 \mathrm{MeV}$ & Average value \\
\hdashline $40 \mathrm{MV}$ & $7.9 \times 10^{11}$ & $4.0 \times 10^{11}$ & $6.0 \times 10^{11}$ \\
$50 \mathrm{MV}$ & $1.9 \times 10^{12}$ & $1.0 \times 10^{12}$ & $1.5 \times 10^{12}$
\end{tabular}

(ס) Energy involved in the flare. First we consider the thick-target case. For a spectrum having the form $P_{0}^{-1} \exp \left(-P / P_{0}\right)$ and for non relativistic protons, the average proton energy is $P_{0}^{2} / \mathrm{Mc}^{2}$; thus for the thick-target model the energies carried by $2 \times 10^{36}$ protons and $8 \times 10^{35}$ protons are $5.6 \times 10^{30} \mathrm{erg}$ and $3.5 \times 10^{30}$ ergs for 40 and $50 \mathrm{MV}$ respectively.

For the thin target model the rate of gamma photon production and the proton energy loss rate depend on the product of the ambient density and the number of protons emitted (Ramaty and Lingenfelter, 1973). The ratio of these two rates is independent of $n$ and $N$ depends on the accelerated proton spectrum, i.e. on $P_{0}$. Table $\mathrm{V}$ gives the energy lost by a proton with rigidity above 0 for $n=1 \mathrm{~cm}^{-3}$ and for various characteristic rigidities. 
Between 40 and $50 \mathrm{MV}, \mathrm{W}$ is about $1.9 \times 10^{-18} \mathrm{erg} \mathrm{s}^{-1}$ (Table V). Using the values for $n$ and $N$ given above, for the energy involved expressed in erg $\mathrm{s}^{-1}$ we have:

$\begin{array}{llll}\text { Proton rigidity } & 4.43 \mathrm{MeV} & 6.14 \mathrm{MeV} & \text { Average value } \\ 40 \mathrm{MV} & 3.7 \times 10^{29} & 1.9 \times 10^{29} & 2.8 \times 10^{29} \\ 50 \mathrm{MV} & 2.1 \times 10^{29} & 1.1 \times 10^{29} & 1.6 \times 10^{29}\end{array}$

Since the event lasted $8 \mathrm{~min}$, the total energy involved, expressed in ergs, is:

\begin{tabular}{llll} 
Proton rigidity & $4.43 \mathrm{MeV}$ & $6.14 \mathrm{MeV}$ & Average value \\
\hline $40 \mathrm{MV}$ & $1.8 \times 10^{32}$ & $9.1 \times 10^{31}$ & $1.3 \times 10^{32}$ \\
$50 \mathrm{MV}$ & $1.0 \times 10^{32}$ & $5.5 \times 10^{31}$ & $7.7 \times 10^{31}$
\end{tabular}

This corresponds to an average energy $1.2 \times 10^{32}$ ergs involved in the entire $\gamma$-ray event.

\section{Conclusion}

After a general description of the 2 events on August 2 and 7, we have tried to present some evidence of the presence of $\gamma$-ray lines during these two events. It seems that for the August 2 event a line at $0.511 \mathrm{MeV}$ is revealed but this does not exclude definitively the possibility of an X-ray continuum extending to about $600 \mathrm{keV}$. For the August 7 event, the evidence of high energy $\gamma$-rays up to $8 \mathrm{MeV}$ is clearly shown, but as we have no spectral information between $500 \mathrm{keV}$ and $3 \mathrm{MeV}$ it is still difficult to estimate a continuum $\gamma$-ray contribution. We have nevertheless attempted to do it, but our results seem to be more consistent with the presence of lines at 4.43 and $6.14 \mathrm{MeV}$, if the Ramaty-Lingenfelter theory is used. Obviously without the support of this theory, it will be impossible to say anything about the origin of the observed $\gamma$-ray excess.

In any case it appears that the durations for the $\mathrm{X}$ - and $\gamma$-ray emission during the 7 August event are quite different, which seems to indicate a different origin for these emissions. In fact this is quite possible, even if there is only continuum, because, as Chupp et al. (1972) point out the origin of this continuum may not be entirely related to the presence of high energy electron bremsstrahlung and other lines, not resolved and associated with proton interactions, may contribute.

If as we think the excess of $\gamma$-ray flux recorded by our experiment can be attributed to proton interactions in solar atmosphere, the reasonably good time correlation at the beginning of the $\mathrm{X}$ - and $\gamma$-ray events seems to prove that the non-relativistic and mildly relativistic energy electrons are accelerated at about the same time as the relativistic electron and high energy protons (Švestka, 1973). 


\section{Acknowledgements}

The authors wish to thank Mr. F. Cambou, I. A. Savienko, N. N. Volodichev, and A. A. Souslov, Mrs E. I. Morozova and Mr. N. I. Nazarov for their assistance in this work, as well as Mr F. Cotin for his great contribution to the preparation of the experiment.

\section{References}

Blioudov, V. A., Voloditchev, N. N., Grigorov, N. L., Kusine, Y. N., Likine, O. B., Netchaev, Y. Y., Podolsky, A. N., Savenko, I. A., Suslov, A. A., Ustinov, V. M., and Dritchikov, X.: 1974, Geomagnetism i Aeronomiya 13, 1029.

Bostrom, C. O., Kohl, J. W., Mc Entire, R. W., and Williams, D. J.: 1972, 'The Solar Protons Flux - August 2-12, 1972', Preprint, The Johns Hopkins University, Silver Spring, Maryland. Brown, T.: 1972, Solar Phys. 26, 441.

Bui-Van, A., Giordano, G., Hurley, K., and Mandrou, P.: 1973, 'A Monte Carlo Program for Scintillation Counter Response, C.E.S.R. report 73-382 - August.

Castelli, T. P., Barron, W. R., and Aarons, T.: 1973, Solar Radio Activity in August 1972, AFCRLTR-73-0086.

Chupp, E. L., Forrest, D. J., and Suri, A. N.: 1972, 'Solar Gamma Ray and Neutron Observations', Max Planck Institut für Physik and Astrophysik - M.P.I.-PAE/Extraterr. 77.

Chupp, E. L., Forrest, D. J., and Suri, A. N.: 1973a, Gamma Ray and Neutron Measurements and Their Relation to the Solar Flare Problem', 16th Meeting of Cospar, Konstanz, May-June.

Chupp, E. L., Forrest, D. J., Higbie, P. R., Suri, A. N., Tsai, C., and Dunphy, P. P.: 1973b, Nature 241, 333.

Chupp, E. L., Forrest, D. J., and Suri, A. N.: 1974, Private communication.

Datlowe, D. W. and Peterson, L. E.: 1973, 'OSO-7 Observation of Solar X-Ray Bursts from 28 July to 9 August 1972', Report UAG-28, II, 291.

Dodge, J. C.: 1973, 'Interferometric Radio Spectrum of the Solar Corona, 1-11 August 1972 in Collected Data Reports on August 1972 - Solar Terrestrial Events', World Data Center, A, Report UAG-28, Part I, 242.

Grigorov, N. L., Melioransky, A. S., Nazarov, N. N., Pankov, V. M., Savenko, I. A., and Spirnov, S. P.: 1974, Geomagnetism i Aeronomiya, (in press).

Kudriavtsev, M. I., Likine, O. B., Melioransky, A. S., Savenko, I. A., Smirnov, V. V., and Chamoline, V. M.: 1973, Geomagnetism i Aeronomiya 13, 406.

Lincoln, J. V. and Leighton, H. J.: 1972, 'Preliminary Compilation of Data for Retrospective World Interval July 26-August 14, 1972', World Data Center A., Report UAG-21, 1972a.

Ramaty, R. and Lingenfelter, R. E.: 1973, Nuclear Gamma Rays from Solar Flare, NASA X-66073-14.

Reppin, C., Chupp, E. L., Forrest, D. J., and Suri, A. N.: 1973, 'Solar Neutron Production during the Events on 04 and 07 August 1972', 13th Int. Cosmic Ray Conf., Denver, August 1973.

Straka, R. M.: 1970, 'The Use of Solar Radio Bursts as Predictors of Proton Event Magnitude, AFCRL Space Forecasting Research Note, June 1970.

Švestka, Z.: 1973, 'Critical Problems of Solar Flare Research', 16th Meeting of Cospar, Konstanz, May-June.

Valnicek, B., Farnik, F., Horn, J., Letfus, V., Sudova, J., Komarek, B., Engelthaler, P., Ulrych, J., Moucka, L., Fronka, O., Vasek, T., Beranek, I., Pich, J., and Zderadicka, J.: 1973, Bull. Astro. Inst. Czech. 24, No. 6.

Van Beek, H. F., Hoyng, P., and Stevens, G. A.: 1973, 'Solar Flares Observed by the Hard X-Ray Spectrometer on Board the ESRO TD1-A Satellite', Report UAG-28, II, 319.

Vedrenne, G., Talon, R., and Cotin, F.: 1973, 'Experience SIGNE 1', - C.E.S.R. Report 73-364, Avril, Toulouse, France.

Wang, H. T. and Ramaty, R.: 1974, Solar Phys. 36, 129.

Zirin. H. and Tanaka, K.: 1973, Solar Phys. 32, 173. 